\title{
EDUCAÇÃO ESPECIAL NA PERSPECTIVA INCLUSIVA E O SERVIÇO DO ATENDIMENTO EDUCACIONAL ESPECIALIZADO: DA ESCOLA A UNIVERSIDADE
}

\author{
Educación Especial en una perspectiva inclusiva y el servicio de la atención \\ educativa especializada: de la escuela a la universidad
}
Special Education under an inclusive perspective and specialized education services: from regular schools to universities

Mirlene Ferreira Macedo Damázio ${ }^{1}$

\begin{abstract}
Resumo
Este texto objetiva dialogar sobre a educação especial em uma perspectiva inclusiva com enfoque na metodologia do serviço do Atendimento Educacional Especializado (AEE) na escola e na universidade. Abordamos a legalidade desse serviço enfatizando a Política atual de Educação Especial em uma perspectiva inclusiva. Detalhamos o projeto e sua metodologia de pesquisa, bem como demarcamos o referencial teórico sobre o ser humano e seu desenvolvimento. Exemplificamos o serviço do AEE, destacando doze ações importantes que podem e devem ser aplicadas pelo professor especialista que atua no AEE, quando em atuação nesse serviço em uma escola e/ou universidade. Esclarecemos aspectos essenciais e norteadores da metodologia desse serviço, levando ao aperfeiçoamento do trabalho.
\end{abstract}

PALAVRAS-CHAVE: Educação Especial. Inclusão. Atendimento Educacional Especializado. Metodologia.

\begin{abstract}
This paper aims to discuss Special Education under an inclusive perspective, focusing on the methodology of Specialized Education Services (SES) in regular schools and universities. It is addressing the legality of this service emphasizing the National Policy on Special Education under an inclusive perspective. The project and its research methodology are detailed in this paper, as well as the theoretical reference definition on the human being and its development. The SES is exemplified, underlining twelve important actions that can and should be applied by the SES teacher, during the implementation of this service within a regular school or university. It is to provide clarity on important and notable aspects of this service methodology, leading to the improvement of the work.
\end{abstract}

KEYWORDS: Special Education. Inclusion. Specialized Education Services.Methodology.

\section{Resumen}

El objetivo de este trabajo fue dialogar sobre la educación especial en una perspectiva inclusiva con enfoque en la metodología del servicio de la Atención Educativa Especializada (AEE) en la escuela y en la universidad. Abordamos la legalidad de ese servicio enfatizando la Política actual de Educación Especial en una perspectiva inclusiva. Detallamos el proyecto y su metodología de

\footnotetext{
${ }^{1}$ Doutora em Educação pela Universidade Estadual de Campinas/UNICAMP. Professora Adjunto da Faculdade de Educação da Universidade Federal da Grande Dourados. Chefe do Núcleo Multidisciplinar para a Inclusão e Acessibilidade/NuMIAc. Coordenadora do LAPEI - Laboratório de Práticas em Educação Inclusiva e Líder do SIMBIOSE- Grupo de Estudo em Pedagogias e Diferenças Humanas/FAED/UFGD. E-mail: <mirlenedamazio@ufgd.edu.br>.
} 
investigación, así como demarcamos el referencial teórico sobre el ser humano y su desarrollo. Ejemplificamos el servicio de la AEE, destacando doce acciones importantes que pueden y deben ser aplicadas por el profesor especialista que actúa en la AEE, cuando en actuación en ese servicio en una escuela y/o universidad. Aclaramos los aspectos esenciales y orientadores de la metodología de ese servicio, llevando al perfeccionamiento del trabajo.

PALABRAS CLAVE: Educación Especial.Inclusión. Atención Educativa Especializada. Metodología.

\section{INTRODUÇÃO}

A educação especial em uma perspectiva inclusiva consiste em um movimento de âmbito nacional, envolvendo ações socioculturais, políticas, psicológicas e pedagógicas para garantir às pessoas com deficiência (PCD), transtornos globais do desenvolvimento (TGD), transtornos do espectro autista (TEA) e altas habilidades/superdotados (AH/SD) o direito de estarem juntas nos diversos ambientes independentemente da sua diferença, déficit, falta, falha, insuficiência e/ou deficiência , nos quais devem conviver, aprender e participar, sem nenhum tipo de preconceito ou discriminação. É um paradigma fundamentado na concepção de direitos e valores humanos que agrega infinitas possibilidades para essas pessoas, envolvendo em especial o acesso e a permanência no âmbito escolar com igualdade e equidade.

Entretanto, para esse processo se efetivar é necessário enfrentar os empecilhos e entraves existentes, que não favorecem o pleno exercício de direitos à acessibilidade, envolvendo os bens e serviços, ou seja, qualquer atitude ou comportamento que estabeleça impedimentos a sua participação social, provocando barreiras, as quais, quando analisadas nos sistemas educacionais, dificultam muito a efetivação do ensino e a promoção da aprendizagem. Ao reconhecermos as barreiras existentes, torna-se necessário deflagrar iniciativas que confrontem as atitudes excludentes, discriminatórias e preconceituosas, criando alternativas com o intuito de superá-las. A educação especial, em uma perspectiva inclusiva, assume um espaço complexo no debate, quando legitima a superação da lógica da exclusão e dos marcadores do déficit, falha, falta e evidencia o potencial humano como ponto de partida e premissa singular.

O Brasil, na atualidade, enfrenta um grande desafio, o de se estruturar para se tornar um país que acolhe e respeita as diferenças humanas das pessoas, valorizando seus potenciais individuais e coletivos, relegando o caráter excludente, discriminatório e segregacionista, em especial na educação básica e superior que se organiza, ainda, incorretamente para potencializar a capacidade dessas pessoas (DAMÁZIO; ALVES, 2010). Tornar o espaço da escola e o da universidade brasileira inclusivos perpassa 
mudanças de paradigmas e exige novos “jeitos” de fazer, ou seja, mudar a concepção da estrutura/funcionamento e as práxis pedagógicas.

Conforme a Constituição Federal de 1988, o direito à diferença está previsto e dá o direito à igualdade de acesso à educação. A Lei de Diretrizes e Base da Educação Nacional de 1996 (LDBEN/1996), por sua vez, dispõe que o atendimento educacional especializado (AEE) será realizado sempre que, em função das condições e necessidades específicas dos estudantes, não for possível a sua inclusão. No que diz respeito à Lei Brasileira de Inclusão, Lei 13.146/2015 (LBI/2015), ela garante vários direitos aos 45 milhões de brasileiros com PCD, TGD, TEA e AH/SD e estabelece sanções para atitudes preconceituosas e discriminatórias.

Pelo texto da LBI/2015, questões relacionadas à acessibilidade, à educação e ao trabalho passaram a ser mais discutidas e um dos principais avanços é a inclusão social e educacional. Uma mudança considerada bem relevante e inovadora está no conceito legitimado de deficiência, a qual não é mais entendida como uma condição estática e biológica da pessoa, mas sim como o resultado da interação das barreiras impostas pelo meio com as limitações de natureza física, mental, intelectual e sensorial da pessoa. A deficiência deixa de ser um atributo da pessoa e passa a ser o resultado da falta de acessibilidade que a sociedade e o Estado dão às características de cada um. Ou seja, a LBI/2015 veio para mostrar que a "deficiência está no meio, não nas pessoas". Concluímos, então, que, quanto mais acessos e oportunidades uma pessoa tiver, menores serão as suas dificuldades para viver e conviver.

Ao refletir sobre todas as questões polêmicas que perpassam a discussão acerca da educação no contexto escolar, iniciando pelas leis e enfatizando a Política Nacional de Educação Especial na Perspectiva da Educação Inclusiva de 2008, reformulada em 2011, que legitima a promoção do ensino desde a educação básica até o superior aberto as PCD, TGD, TEA e AH/SD. Várias são as leis que asseguram os direitos dessas pessoas, mas, do que adiantam belas e tracejadas linhas legais, se no âmago ainda se veem poucas mudanças nas atitudes? De que vale um papel, se as pessoas não conseguem mudar a forma de ver a pessoa com diferenças tão singulares? Percebe-se progresso nas leis, mas as modificações estruturais e atitudinais ainda deixam muito a desejar. As leis são necessárias para assegurar os direitos, porém a mudança de mentalidade, envolvendo os novos paradigmas da contemporaneidade, é emergente em busca de uma sociedade mais justa e solidária para a vida em sociedade dessas pessoas. 


\section{O PROJETO E SEU PRESSUPOSTO METODOLOGICO}

A escola e a universidade, que existem em todos os Estados brasileiros, que atendem a um ou a vários estudantes público-alvo da educação especial, devem estar abertas a todos. Para isso, algumas tomadas de posição e compreensão de bases epistemológicas de caráter inclusivo precisam ficar mais claras, a fim de que a escola e a universidade públicas e também privadas apresentem propostas efetivas e produtivas para a educação dessas pessoas. Muitos são os empecilhos e entraves. Assim, para elucidarmos, realizamos desde 2017 uma pesquisa denominada Passo a Passo: metodologia do atendimento educacional especializado, visando investigar colaborativamente as metodologias gerais do serviço e do ensino, procurando compreendê-los e se possível, gerar soluções inovadoras práticas, simples e objetivas, extraídas do cotidiano e referendadas pelas bases epistemológicas concernentes à especialidade desse trabalho.

Adotamos a pesquisa ação crítico-colaborativa como metodologia científica para a execução do presente projeto, por considerarmos e desejarmos desenvolver uma pesquisa com ação e ação com pesquisa, enfim, ação na pesquisa. A metodologia adotada considera a "voz do sujeito, sua perspectiva, seu sentido, mas não apenas para registro e posterior interpretação do pesquisador, a voz do sujeito fará parte da tecitura da metodologia da investigação" (FRANCO, 2005, p. 486). Assim, o sujeito adquire consciência das transformações que vão acontecendo, beneficiando o seu autoconhecimento e melhorando suas práticas educacionais e sociais no processo. Essa metodologia tem um caráter emancipatório, pois favorece a plena participação consciente dos sujeitos da pesquisa e tem oportunidade de libertá-los de preconceitos e reorganizálos para uma nova concepção enquanto sujeito histórico cultural e intercultural, realizando transformações e assumindo compromissos éticos e políticos (FRANCO, 2005, p. 488).

De acordo com Pimenta (2000, p. 14), a pesquisa ação crítico-colaborativa ocorre "quando a busca de transformação é solicitada pelo grupo de referência à equipe de pesquisadores, na qual a função do pesquisador será a de fazer parte e cientificar um processo de mudança anteriormente desencadeado pelos sujeitos do grupo". Nesse contexto, visa superar as lacunas existentes entre a pesquisa educativa e a prática docente, ou seja, entre a teoria e a prática, e os resultados ampliam as capacidades de compreensão 
do professor com relação às suas práticas, favorecendo mudanças nas atitudes e ações criticamente.

A partir desse referencial metodológico, o projeto é aplicado e desenvolvido por doze profissionais especializados que atuam no AEE das escolas municipais, estaduais de Ensino Fundamental da cidade de Dourados/MS, bem como no ensino superior - sendo oito municipais, quatro estaduais e dois de universidade, que oferecem serviço especializado. Os pesquisadores professores da universidade e pesquisadores professores das escolas trabalham de forma participante, coletiva e observadora, investigando os serviços do atendimento especializado e suas metodologias de ensino, e, a partir desse cenário, analisam as possibilidades de aperfeiçoamento do trabalho metodológico.

Diante do exposto e atentos à formação de professores para atuarem na educação especial em uma perspectiva inclusiva e no serviço do AEE da educação infantil ao ensino superior, ressaltamos que o eixo principal de estudo é o ser humano e os atos educativos em favor dele. Assim, no início da pesquisa, fizemos levantamentos bibliográficos sobre dois conceitos importantes que sustentam o fazer pedagógico nesse serviço, envolvendo a compreensão do ser humano e os atos educativos com suas práxis pedagógicas.

\section{SER HUMANO EM QUESTÁO: construindo referenciais}

Ser cidadão é estar cônscio de seus direitos e deveres, bem como estar preparado para usufruir da realidade sociocultural, com seus bens e serviços, criando as infinitas possibilidades para o bem viver. Portanto, quais as mudanças necessárias para atuarmos, criando possibilidades, rompendo com os entraves e empecilhos, organizando e sistematizando informações, gerando mudanças em nossa realidade, em especial no contexto de nossas escolas e universidades em favor do desenvolvimento das pessoas, em especial das PCD, TGD e AH/SD?

Precisamos romper com a visão cartesiana, baseada em verdades, deduções puras e evidências por si mesmas, sem considerar a subjetividade eminente que envolve o meio ambiente e as pessoas. Sob outro aspecto, em uma visão sistêmica, temos uma concepção ampliada de homem e de mundo, em que as conexões, as interatividades e a interdependência dos fenômenos provocam trocas em processos complementares, criando formas e jeitos de fazer as coisas diferentes, rompendo com a visão cartesiana. Desse modo, passamos a compreender o ser humano em uma dimensão biopsicossocial, 
cognitivo-cultural, considerando a importância de observá-lo, bem como suas interações nos diferentes contextos e sistemas (BRONFENBRENNER, 1979).

Bronfenbrenner (1979) afirma que o desenvolvimento humano é definido como um conjunto de processos, envolvendo particularidades da pessoa e do ambiente em simbiose para produzir ritmos e mudanças nas características da pessoa no curso da vida. Nessa abordagem, o desenvolvimento é uma transformação que atinge a pessoa, e não é de caráter passageiro, situacional ou de um dado contexto. Trata-se de uma reorganização continuada envolvendo tempo e espaço. Essa reorganização se dá em diferentes níveis de vida da pessoa, abrangendo as ações empreendidas, as atividades executadas e as diversas interações com o seu meio circundante. As interações estimulam ou podem inibir o desenvolvimento humano, dependendo da variedade de papéis que desempenha e a efetiva participação e engajamento no ambiente social.

Quando a pessoa está vivenciando uma situação social, seja na família, escola ou na universidade, ela entra em contato com diferentes papéis, como o do professor, colegas, mãe, pai, irmãos, tios, avós, e tem a oportunidade de estabelecer repertórios distintos para cada uma das interações. Esse aprendizado se dá pela interação nas vivências cotidianas, que são ricas de solicitações e favorecem infinitas possibilidades ao pensar e agir da pessoa. Portanto, o desenvolvimento humano estabelece-se de maneira contínua e recíproca entre aspectos biológicos, psicológicos e ambientais, em que as características biopsicológicas da pessoa sofrem alterações, transformando a pessoa e o seu ambiente permanentemente. O desenvolvimento, nessa perspectiva, é conceituado e investigado como um processo,

Assim sendo, Bronfenbrenner (1979) ressalta que o ser humano é protagonista e ativo em seu desenvolvimento, rompendo com as ideias que concebem o ser humano como passivo, que apenas recebe influências do ambiente sem nele poder intervir. Essa abordagem nos leva a uma visão sistêmica do ser humano, abrangendo o genético, o comportamental e o ambiental, ou seja, físico, social e cultural, que se integram ao longo do tempo nas suas rotinas cotidianas, ou seja, uma ampla compreensão de sistemas interdependentes que agem dinamicamente e exercem influência sobre o desenvolvimento humano.

Precisamos compreender o homem e o mundo relacionados entre si, procurando desenvolver uma ação entre o conhecedor, o conhecimento e o conhecido de maneira dimensionada e ampliada. Essa ação não fica restrita ao conhecimento do mundo físico, 
dos objetos no plano concreto; ela também se realiza por meio de exercícios reflexivos, intuitivos e relacionais, baseados na complexidade do fenômeno inter e intra-humano e no meio vivencial, de forma processual, gradativa, que exige muita investigação e atos educativos ligados à necessidade do homem, por meio de sistemas contextuais e complexos que são auto-organizados (MORAES, 1997).

Criando uma compreensão do homem, do objeto e do conhecimento numa tríade única, indivisível, esse poderá falhar, acertar e refazer caminhos, alcançando, por meio de seu autoconhecimento e do reconhecimento do outro, um encontro interior e exterior e atingindo o processo de busca natural transformando-se. Logo, estabelecem-se princípios que compreendem o homem como um ser histórico, dialógico, ético, estético, no qual desperta a consciência de si mesmo, possuindo aptidões individuais, naturais e culturais. Nesse conjunto, os princípios básicos e científicos orientam o entendimento que ocorre com o ser humano em busca de sua evolução, a partir da compreensão do ciclo de desenvolvimento e aprendizagem humana natural, social, emocional e intelectual, por meio das várias ciências; da compreensão da aptidão, do interesse, da habilidade e dos talentos humanos, envolvendo uma interação sinergética de quatro núcleos conectados: a pessoa, o processo, o contexto e o tempo (BRONFENBRENNER, 1979).

Nesse sentido, precisamos desenvolver um campo de trabalho comprometido com a formação humana e profissional, visando possibilitar um convívio com a realidade, de maneira contextualizada, compreendendo seus aspectos condicionantes e ideológicos e propondo possíveis alternativas às questões-problemas, que deflagram as habilidades para interpretar o mundo na visão da virtualidade, da sustentabilidade, da inteireza, da plenitude e da visão ecológica; ver o homem no mundo como um fenômeno complexo, no qual a incerteza, a indefinição, a incompletude, a complementaridade são elementos para sua reflexão/ação; compreender ideias e valores socioculturais e históricos, indispensáveis aos atos do homem no mundo; compreender o conhecimento e as coisas do mundo de maneira conectada e contextualizada, construindo significados, sentidos e aplicabilidade na vida; inter-relacionar os saberes adquiridos com os fazeres cotidianos, buscando avanços individuais e coletivos; criar e recriar conhecimentos que são direta e indiretamente relacionados aos atos humanos e seu bem viver (MORAES, 1997).

Nesse aspecto, o foco da atenção recai permanentemente no aproveitamento de toda e qualquer possibilidade existente na pessoa, visando favorecer a oportunidade de ela vir a ser o que pode ser, e não o que queremos, isto é, que ela seja compreendida pelos 
padrões de normalidade e nas respostas esperadas e determinadas. Nesse sentido, o ambiente de aprendizagem é organizado a partir do pressuposto de que todas as pessoas são diferentes e, por isso, são necessárias atitudes e posturas de respeito às limitações de todos, inclusive das pessoas com diferenças humanas provocadas pelas deficiências, transtornos e altas habilidades/superdotação.

A partir dos referenciais teóricos que consideramos até o presente momento ao longo do texto, buscaremos exemplificar as várias alternativas existentes para desenvolvermos os atos educativos da educação especial em uma perspectiva inclusiva, com o serviço do AEE, atendo-se aos estudantes público-alvo. Partimos da premissa do potencial que esses estudantes têm e da necessidade de criarmos os ambientes adequados aos atos educativos, contemplando o que é específico, próprio das PcD, TGD e AH/SD.

\section{ATOS EDUCATIVOS DO SERVIÇO DA EDUCAÇÃO ESPECIAL DO AEE: construindo referenciais}

O Decreto-lei 7.611, de 17 de novembro de 2011, organiza o AEE enquanto um serviço da educação especial em uma perspectiva inclusiva, em favor do público-alvo. $\mathrm{O}$ objetivo é garantir a participação, o acesso, a permanência e a aprendizagem desses estudantes, promovendo respostas às suas necessidades específicas, e assegurar a transversalidade da educação especial desde a educação infantil até o ensino superior, bem como a formação de professores, o envolvimento com a família e a intersetorialidade com a comunidade.

A legislação brasileira objetiva oferecer um sistema educacional inclusivo, de forma gratuita, compulsória em todos os níveis de ensino, sem discriminação, com base na igualdade de oportunidades a todas as pessoas, em especial, ao público-alvo da educação especial, resguardando o aprendizado ao longo de toda a vida de forma acessível, contemplando efetiva aprendizagem de acordo com as necessidades específicas e individuais, com adoção de medidas de apoio individualizado que maximizem o desenvolvimento acadêmico e social.

O AEE deve apoiar o desenvolvimento do estudante com deficiência, transtornos globais de desenvolvimento, transtorno do espectro autista e altas habilidades/superdotados em todos os níveis de ensino da educação brasileira, inclusive, na educação dos jovens e adultos, educação indígena, educação do campo e educação quilombola, disponibilizando o ensino de linguagens e códigos específicos de 
comunicação e sinalização, de tecnologia assistiva, adequar e produzir materiais didáticos e pedagógicos, tendo em vista as necessidades específicas dos estudantes, oportunizando complementação e suplementação curricular.

Esse serviço ofertado exige formação e atuação diferenciadas dos professores, envolvendo conhecimentos específicos, tais como: Língua de Sinais Brasileira (Libras), Língua Portuguesa na modalidade escrita, como segunda língua para pessoas com surdez; sistema braile, sorobã, orientação e mobilidade, utilização de recursos ópticos e não ópticos; atividades de vida autônoma; tecnologia assistiva; processo de ensino e aprendizagem norteados pelas funções mentais superiores; adequação e produção de materiais didáticos pedagógicos; acolhimentos e elaboração de planos de AEE ou PDI para estudantes com altas habilidades/superdotados com programa de suplementação curricular. Todas as ações envolvem especificidades das metodologias de atuação, seja de forma ampla no contexto da escola ou universidade ou no ensino.

Outo aspecto importante é que o AEE deve ser contemplado nas propostas curricular das escolas e universidades e poderá envolver no mínimo doze ações diferenciadas, dependendo do perfil do estudante em atendimento. Todas as ações e atividades realizadas pelo AEE diferenciam-se das que ocorrem em salas de aula da escola comum e da universidade. No cotidiano, o professor especialista atua de maneira flexível, dinâmica, estabelecendo interlocuções e provocando movimentos ao efetivo trabalho. A seguir, alguns dos serviços desenvolvidos pelo professor especialista na escola e universidade, em uma perspectiva inclusiva:

1. Acolhimento inicial e elaboração do plano de AEE ou PDI de acordo com o perfil do estudante;

2. Atendimento individual ao estudante ou em subgrupo;

3. Adequação de material pedagógico e tecnologia assistiva (TA);

4. Apoio e assessoria ao estudante em sala de aula e/ou laboratórios;

5. Apoio e assessoria ao professor na sala de aula e/ou laboratórios;

6. Apoio e assessoria ao professor de estágios, laboratórios, artes, educação física;

7. Apoio e assessoria ao profissional de apoio escolar;

8. Apoio e assessoria aos monitores, cuidadores e/ou estagiários;

9. Apoio e assessoria aos gestores (diretores e coordenadores - pedagógicos e de cursos);

10. Apoio e orientações à família do estudante; 
11. Ações intersetoriais - saúde e ação social;

12. Elaboração de pareceres e relatórios descritivos analíticos de cunho pedagógico.

É possível compreender que a atuação do professor especialista no serviço do AEE em ações inclusivas não é apenas atender ao estudante individualmente, e, sim, realizar interlocuções com os demais profissionais e setores da escola e da universidade de forma direta ou indireta em favor de seu desenvolvimento. Entendemos que, se o professor especializado atuar em apenas uma das ações supramencionadas, ele não conseguirá realizar o serviço sob uma perspectiva inclusiva, como prescreve a política, reproduzindo mais uma vez a concepção segregada e/ou integracionista. Portanto, é preciso compreender que esse serviço da educação especial, oferecido na escola e universidade, deve contemplar a transversalidade, complementaridade, interlocuções e conexões, ou seja, uma visão sistêmica da educação especial dentro da escola e nos núcleos de acessibilidade das universidades com o serviço do AEE.

Nesse sentido, a atuação transversaliza o serviço no contexto da escola e da universidade. É um processo dinâmico, dialógico e cheio de movimentos, procurando estabelecer uma postura inclusiva perante o público-alvo da educação especial. $O$ professor especialista tem a função de organizar o serviço do AEE em uma perspectiva inclusiva, conforme prescrevem as leis brasileiras. A seguir, vejamos as ações do serviço da educação especial - o AEE a serem realizadas nas escolas e universidades:

\section{Acolhimento inicial e elaboração do plano de AEE de acordo com o perfil}

\section{do estudante}

Ao ser matriculado na escola e/ou universidade, o estudante é identificado pelo setor de matrícula e encaminhado ao núcleo de acessibilidade para iniciar o acolhimento, o qual favorece ao estudante a oportunidade de se situar, bem como promover a socialização inicial. Em seguida, começa a coleta de dados para a elaboração do plano de AEE ou Plano de Desenvolvimento Individual (PDI). Geralmente, o professor especializado no serviço do AEE necessita de 45 dias para coletar dados, sistematizá-los, concluir e especificar as necessidades do estudante no plano. O plano é um documento extremamente importante, que assegura direitos e deveres aos profissionais e aos estudantes. Ele norteará todo o processo que será desenvolvido em favor do estudante, envolvendo recursos humanos e materiais. É prudente que o plano seja revisado de seis 
em seis meses, a fim de garantir o pleno acompanhamento do estudante no decorrer da formação acadêmica.

\section{Atendimento individual ao estudante ou em subgrupo}

Esse atendimento é definido a partir o plano de AEE ou PDI, ou seja, deve constar qual tipo de atendimento o estudante vai precisar: individual ou em subgrupo. Ao ser definido, ficarão evidenciados o perfil do estudante e as necessidades específicas. Ao atender individualmente ou em subgrupo, o professor especialista delineará a prática pedagógica a ser aplicada, envolvendo principalmente os atos de estudos, autonomia intelectual, aprendizado de tecnologia assistiva de alta e baixa resolução; processo de ensino e aprendizagem com as adequações e produções de materiais didáticos pedagógicos específicos. Essas funções delinearão o atendimento especializado, procurando dar subsídios complementares ou suplementares ao trabalho do docente.

\section{Adequação de material pedagógico e tecnologia assistiva (TA)}

Outro aspecto importante a ser contemplado no plano de AEE e ou PDI é a necessidade de os estudantes utilizarem alguma TA. É responsabilidade do professor especializado avaliar pedagogicamente o estudante e buscar apoio intersetorial com outras áreas, visando a avaliação funcional para definir qual TA se aplica e, em seguida, preparar e orientar o estudante para utilizá-la. Inicia-se o trabalho preparando-o para o uso da TA. O professor especialista do AEE tem responsabilidade por esse processo de adequação pedagógica, compreendendo desde uma tecnologia de baixa ou alta resolução.

\section{Apoio e assessoria ao estudante em sala aula}

O apoio e a assessoria do professor do AEE ao estudante com deficiência, TGD, TEA, AH/SD dentro da sala de aula envolvem um olhar completo às necessidades dele, conforme descrito no plano. O professor especializado vai apoiar e assessorar o estudante em questões específicas de cunho pedagógico envolvendo o uso de TA, código de linguagens e a sua aprendizagem, dedicando atenção aos estilos de aprendizagem, além de assessorar o estudante em sua organização didática e orientações aos atos de estudo. Esse processo é dinâmico e o professor especializado deve percorrer as salas e apoiar, assessorar, qualquer situação que envolva o estudante em sala de aula, afinal, tudo o que o AEE faz é para complementar o trabalho da sala de aula, ou seja, atingir os objetivos acadêmicos, ajudando-o a evoluir em seu percurso de formação. 


\section{5. $O$ apoio e a assessoria ao docente}

O apoio e a assessoria do professor especializado ao docente em sala de aula configuram-se como um trabalho sistemático, a partir do plano do estudante. O professor especializado orienta o docente a respeito do uso de TA, orientação e mobilidade, linguagens e adequação pedagógica de atividades e provas. O docente da sala de aula é informado sobre a melhor forma de conduzir o trabalho com o profissional de apoio escolar, monitor e/ou estagiário que esteja ajudando-o em sala. Esse auxílio que o docente recebe de outros profissionais dentro da sala é complexo e envolve uma dinâmica pedagógica diferenciada, primando pela autonomia, independência e desenvolvimento do estudante.

O professor especialista orienta o docente sobre como sensibilizar a turma para uma boa convivência com as diferenças, resguardando a interação social. A turma sempre é observada em seu todo e deve valorizar diversificadas formas para desenvolver uma ambiência pedagógica colaborativa e interativa.

\section{Apoio e assessoria ao professor de estágio, laboratório, Artes e Educação}

\section{Física}

O apoio e a assessoria do professor especialista ao professor de laboratórios, estágios supervisionados e outras especificidades configuram-se também como um trabalho sistemático, a partir do plano do estudante. O professor especialista acompanhará a metodologia, os procedimentos e os recursos de ensino escolhidos e utilizados pelo docente da aula, levando-o a refletir sobre a melhor forma de participação do estudante. O professor especialista apoiará o docente a buscar maneiras diferenciadas para contemplar o potencial dos estudantes com PCD, TGD e AH/SD no contexto das disciplinas, envolvendo o participar, o interagir e o expressar.

\section{Apoio e assessoria ao profissional de apoio escolar}

O apoio e a assessoria do professor especializado aos profissionais de apoio escolar acontecem a partir da definição da necessidade desse profissional que tem estudante com necessidades específicas. Ao iniciar o trabalho, esse profissional deve ser acolhido pelo professor especialista, que vai realizar toda a orientação a partir do plano do estudante, atendendo às necessidades específicas deste. O professor orienta sobre o acolhimento do estudante, sistema de comunicação, orientação, mobilidade e adequações pedagógicas. Realiza acompanhamento sistemático, esporádico e de acordo com a 
necessidade desse profissional, assegurando que o trabalho promova a autonomia e a independência dele.

\section{Apoio e assessoria aos monitores e/ou estagiários}

O apoio e a assessoria aos monitores e/ou estagiários acontecem a partir da definição da necessidade que tem o estudante com necessidades específicas. Ao iniciar o trabalho, esses profissionais devem ser acolhidos pelo professor especialista, que iniciará toda a orientação a partir do plano, atendendo às necessidades específicas dos estudantes. O professor especialista orienta sobre o acolhimento dos estudantes, sistema comunicação, orientação/mobilidade e adequações pedagógicas. Realiza acompanhamento sistemático, esporádico e de acordo com a necessidade desses profissionais, assegurando que o trabalho promova a autonomia e independência dele.

\section{Apoio e assessoria aos gestores (direção e coordenadores pedagógicos)}

O apoio e a assessoria do professor especialista aos gestores acontecem a partir do acolhimento desses estudantes, sua matrícula e a enturmação. As necessidades específicas dos estudantes são definidas pelo plano e fornecerão todas as orientações aos gestores sobre a forma de conduzir as dimensões administrativas e pedagógicas, envolvendo recursos humanos, materiais, bem como os procedimentos pedagógicos específicos a serem adotados pelos funcionários envolvidos no trabalho. $\mathrm{O}$ professor especialista tem a função, como profissional da educação especial na escola e no núcleo de acessibilidade da universidade, de colaborar com a inclusão desses estudantes, de realizar o acompanhamento sistemático e, de acordo com a necessidade dos gestores, assegurar que o trabalho aconteça em favor desses estudantes.

\section{Apoio e orientações à família}

O apoio e as orientações à família ocorrerão a partir do relato e estudo do caso. Conforme as necessidades apontadas no plano, o professor especialista realiza orientações aos pais no sentido de ajudá-los na condução dos atos educativos em favor do filho. Todas as orientações são norteadas pelos aspectos definidos no plano. Esperase, com esse apoio e orientação à família, um maior desenvolvimento do estudante, promovendo sua autonomia e independência.

\section{Ações intersetoriais - saúde e ação social}

O professor especialista, a partir do momento que faz o acolhimento do estudante, inicia a coleta de dados sobre ele e, em seguida, escreve e analisa o caso, organizando o plano, no qual ficará definido se haverá a necessidade de ações intersetoriais com a saúde 
e assistência social. Essas ações intersetoriais são previstas nas leis brasileiras, visando ações colaborativas de outros setores que auxiliam também no desenvolvimento das PCD, TGD e AH/SD, garantindo saúde física, mental e bem-estar social.

12. Elaboração de pareceres e relatórios descritivos analíticos de cunho pedagógico

O professor especialista tem como atribuição permanente a elaboração e a emissão de pareceres e relatórios pedagógicos descritivos e analíticos, visando oferecer informações, bem como sistematizar o trabalho desenvolvido. A escola e a universidade, com seu núcleo de acessibilidade, estabelecerão os instrumentos que serão seguidos pelos professores especialistas. É importante que os pareceres e os relatórios contemplem os seguintes aspectos relacionados ao desenvolvimento do estudante: cognição, afetividade, sociabilidade, linguagem/comunicação, atenção e motricidade.

\section{Considerações finais}

Diante do exposto, conclui-se que essas doze ações descritas acontecem de forma sistemática e/ou esporádica no cotidiano da metodologia de trabalho do professor do AEE em uma perspectiva inclusiva na escola e na universidade com seu núcleo de acessibilidade. Se o professor atua apenas atendendo o estudante e não realiza as diversas ações, ele faz o serviço de forma segregada, ou seja, a educação especial não estará na perspectiva inclusiva. Realizar o serviço do AEE na perspectiva inclusiva é ter uma visão sistêmica, norteando o serviço e evitando novamente a exclusão e a segregação desses estudantes.

Ao desenvolver o serviço do AEE em uma perspectiva inclusiva, o professor especialista não transforma a escola e/ou a universidade em inclusiva, mas colabora com a construção desse paradigma no contexto geral, incitando atitudes e provocando conflitos conceituais. Entendemos que, para que tudo isso ocorra, são necessárias atitudes políticoeducacionais, em que o movimento no contexto da escola e da universidade deverá ser gerado a partir do bom entendimento desse serviço da educação especial.

Existem muitas confusões e equívocos sobre o "como" realizar o serviço do AEE dentro da escola e da universidade. Dessarte, esse texto vem elucidar tais aspectos, procurando colaborar com a produção científica nessa área a partir do paradigma da complexidade, em uma abordagem pós-crítica, em que o desenvolvimento e a aprendizagem humana tenham como foco o movimento relacional, tecido em rede, que oriente o diálogo com todas as ciências. Isso provoca a construção da convergência, da 
complementaridade entre conhecimento, desenvolvimento e aprendizagem, evidenciando o uno no múltiplo, do múltiplo no uno, do diferente no uno e do uno no diferente, em que trabalhos e práticas se constituem no individual e no coletivo, o coletivo no individual, como nos ensina Morin (2001).

Portanto, apresentamos doze ações metodológicas do serviço do AEE transversalizado na escola e na universidade, colaborando com o pleno desenvolvimento e aprendizagem dos estudantes. Negar aos estudantes público-alvo da educação especial a possibilidade de estudar em uma universidade, em nome de seu déficit, falha e falta, é, a nosso ver, um grande equívoco teórico-educacional, pois as possibilidades são inúmeras, se organizarmos corretamente o serviço da educação especial no contexto da escola e da universidade.

É preciso refutar as propostas de educação das PcD, TGD e AH/SD que não sejam inclusivas, pois discriminam e deixam os estudantes à parte dos demais. Assim sendo, é necessário romper com esses modelos de escola e universidades excludentes, que prejudicam o desenvolvimento da pessoa ao canalizar a atenção para o problema: a limitação. $\mathrm{O}$ fracasso escolar desses estudantes tem muito a ver com as atitudes e as práticas pedagógicas empreendidas a todos os estudantes, indistintamente.

\section{REFERÊNCIAS}

BRASIL, Ministério da Educação e do Desporto. Lei de Diretrizes e Bases da Educação: Lei n. ${ }^{\circ}$ 9394/96, de 20 de dezembro de 1996, Brasília. de 1988 .

Constituição Federal. Brasília: Imprensa Oficial. Promulgada em 5 de outubro

Política nacional de educação especial na perspectiva da educação inclusiva. Brasília: MEC; $\quad 2008 . \quad$ SEESP, Disponível em: $<$ http://portal.mec.gov.br/index.php?option=com_docman\&view=download\&alias=166 90-politica-nacional-de-educacao-especial-na-perspectiva-da-educacao-inclusiva>. Acesso em: 5 out. 2017.

$\begin{array}{ccccc} & \text { Lei n. } & \text { 13.146, de } 6 \text { de julho de } & \text { 2015. Dispõe sobre a Lei Brasileira de Inclusão } \\ \text { da } & \text { Pessoa } & \text { com } & \text { Deficiência. }\end{array}$ <http://www.planalto.gov.br/ccivil_03/_Ato2015-2018/2015/Lei/L13146.htm>. Acesso em: 5 out. 2017.

BRANDÃO, C. R. O que é educação? São Paulo: Brasiliense, 1981.

BRONFENBRENNER, U. A ecologia do desenvolvimento humano: experimentos naturais e planejados. Porto Alegre: Artes Médicas, 1979. 
DAMÁZIO, M. F. M.; ALVES, C. B. Atendimento educacional especializado do aluno com surdez. São Paulo: Moderna, 2010.

FRANCO, M. A. R. S. A pedagogia da pesquisa ação. In: ENCONTRO NACIONAL DE DIDÁTICA E PRÁTICA DE ENSINO, 12, 2005, Curitiba. Anais... Curitiba: Endipe, 2005.

MORAES, Maria Cândida. O paradigma educacional emergente. 3. ed. Campinas: Papirus, 1997.

MORIN, E. Introdução ao pensamento complexo. 3. ed. Lisboa: Stória, 2001.

PIMENTA S. G. et al. Pesquisa colaborativa na escola como abordagem facilitadora para o desenvolvimento da profissão de professor. In: MARIN, A. J. (Org.). Educação continuada. Campinas: Papirus, 2000.

Recebido em: 03/10/2017

Aprovado em: 27/01/2018 